Monográfico: Reflujo Vesicoureteral

Arch. Esp. Urol., 61, 2 (213-217), 2008

\title{
REFLUX IN CYSTOPLASTIES
}

\author{
Rosalia Misseri, David H. Rosenbaum and Richard C. Rink.
}

Pediatric Urology. James Whitcomb Riley Hospital for Children. Indiana University School of Medicine. Indianapolis. USA.

Summary.- Vesicoureteral reflux is a commonly encountered condition in pediatric urology. The treatment of vesicoureteral reflux is debated in all patients. Much controversy exists regarding the need to reimplant refluxing ureters at the time of bladder augmentation, particularly in those patients with neuropathic bladders. In patients with neuropathic bladders, reflux may be the result of elevated detrusor pressure, recurrent/persistent urinary tract infections and/or a neuropathic dysfunction at the ureterovesical junction and the trigone. Treatment of VUR in patients undergoing bladder augmentation varies and includes routinely reimplanting all refluxing ureters, selectively reimplanting ureters with high-grade reflux or avoiding anti-reflux surgery in all patients regardless of the grade of reflux. We review the literature and our experience with the treatment of vesicoureteral reflux in patients that have undergone augmentation cystoplasty.

\begin{tabular}{|c|c|}
\hline & $\begin{array}{l}\text { Pediatric Urology } \\
\text { James Whitcomb Riley Hospital for Children } \\
\text { Indiana University School of Medicine } \\
702 \text { Barnhill Drive, ROC } 4230 \\
\text { Indianapolis. IN 46202. (USA) } \\
\text { rmisseri@iupui.edu } \\
\text { rosenbad@iupui.edu } \\
\text { rrink@iupui.edu }\end{array}$ \\
\hline
\end{tabular}

Keywords: Vesicoureteral reflux. Neurogenic bladder. Bladder augmentation.

Resumen.- El reflujo vesicoureteral es una condición frecuente en urología pediátrica. El tratamiento en todos los pacientes está en debate. Existe una gran controversia sobre la necesidad de reimplantar los uréteres refluyentes en el momento de la cistoplastia de aumento, especialmente en aquellos pacientes con vejigas neurógenas. En pacientes con vejigas neurógenas, el reflujo puede ser el resultado de una presión elevada del detrusor, de infecciones del tracto urinario recurrentes/persistentes y/o de una disfunción neuropática de la unión ureterovesical y el trígono. El tratamiento del RVU en pacientes sometidos a cistoplastia de aumento varía, incluyendo desde el reimplante rutinario de todos los uréteres refluyentes hasta la evitación de la cirugía antirreflujo en todos los pacientes independientemente del grado del reflujo. Revisamos la literatura y nuestra experiencia con el tratamiento del reflujo vesicoureteral en pacientes sometidos a cistoplastia de aumento.

Palabras clave: Reflujo vesicoureteral. Vejiga neurógena. Cistoplastia de aumento.

\section{INTRODUCTION}

Vesicoureteral reflux (VUR) is one of the most common problems encountered by pediatric urologists. The overall incidence of VUR in the general pediatric population is estimated to be approximately $1 \%$ (1). However, the prevalence of reflux varies significantly based on age, gender, race and bladder dynamics. Our current focus is to review vesicoureteral reflux in children with particular attention to reflux in patients that are candidates for augmentation cystoplasty. 


\section{VESICOURETERAL REFLUX}

Vesicoureteral reflux may be considered primary or secondary. In primary reflux there is a deficiency in longitudinal muscle at the ureterovesical junction that results in absence of the valvular mechanism necessary to prevent back flow of urine. This is the most common form of reflux encountered and also is the primary mechanism for vesicoureteral reflux in the exstrophy-epsipadias complex. Secondary reflux is the result of functional bladder abnormalities. Patients with neuropathic bladders (e.g., myelodysplasia, spinal cord injuries), non-neurogenic neurogenic bladders, severe voiding dysfunction and posterior urethral valves are at risk for reflux, not because of an intrinsic abnormality in the valvular mechanism, but due to altered bladder dynamics, i.e., elevated bladder pressures overcome the natural resistance of the ureterovesical junction allowing urine to flow in a retrograde fashion. Patients with exstrophy-epispadias complex may also have secondary reflux when bladder capacity is small and bladder compliance is poor.

In untreated or poorly managed children with neuropathic bladders up to $60 \%$ have vesicoureteral reflux (2). Conservative management utilizing clean intermittent catheterization $(\mathrm{ClC})$ and anticholinergic medications will resolve or improve reflux in up to $63 \%$ of cases (3). In a sequential non-randomized trial, Kasabian and colleagues report 92\% of patients treated prophylactically with $\mathrm{CIC}$ and anticholinergics had normal upper urinary tracts after 5 years while $48 \%$ of children treated expectantly had radiographic upper tract changes (4).

The primary goal in the therapy of patients with neuropathic bladders, valve bladders and closed exstrophied bladders, is to prevent upper urinary tract deterioration by maintaining a compliant, low pressure, capacious bladder. This is typically accomplished with the proactive use of anticholinergic medications, $\mathrm{CIC}$ and close followup. Failure of conservative therapy may result in worsening hydronephrosis, VUR, recurrent urinary tract infections and renal insufficiency. When medical therapies fail to achieve a compliant low pressure bladder, augmentation cystoplasty is a widely accepted surgical means of achieving this.

\section{VUR: TO CORRECT OR NOT TO CORRECT AT THE TIME OF AUGMENTATION CYSTOPLASTY?}

Much controversy exists regarding the need to reimplant refluxing ureters at the time of bladder augmentation, particularly in those patients with neuropathic bladders. (5-9). In patients with neuropathic bladders, reflux may be the result of elevated detrusor pressure, recurrent/persistent urinary tract infections and/or a neuropathic dysfunction at the ureterovesical junction and the trigone (10). Treatment of VUR in patients undergoing bladder augmentation varies greatly and includes routinely reimplanting the ureters in all patients, selectively reimplanting ureters with high-grade reflux or avoiding anti-reflux surgery in all patients regardless of the grade of reflux.
The decision to reimplant the refluxing ureter at the time of augmentation is based on concerns that persistent reflux may cause further renal scarring and deterioration. However, VUR in the neuropathic population is most commonly secondary to elevated intravesical pressure. Correcting the bladder dynamics with augmentation should lead to improvement or resolution of the VUR.

Several studies have examined the potential need for reimplant at the time of bladder augmentation. Augmenting the bladder alone (no ureteral reimplantation) has been reported to lead to the resolution of reflux in up to $92 \%$ of patients. Augmentation alone was performed in 14 patients with noncompliant, high-pressure bladders and grade II to grade V VUR (grade II in 5, grade III in 6, grade V in 8 , grade $V$ in 1). Of 14 patients with 20 refluxing ureters that had bladder augmentation alone, Nasrallah and Aliabadi reported resolution in 12 and improvement from grade IV to II in 1 and a "wisp of reflux" in another. Urodynamic evaluations were available in 13, each with "excellent complian-

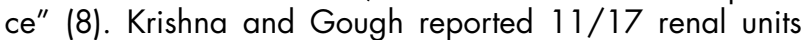
had resolution of VUR while one had improvement after enterocystoplasty to reduce storage pressure below $20 \mathrm{~cm}$ saline and intermittent $\mathrm{CIC}$ (9). In the largest series assessing the outcome of VUR after augmentation cystoplasty alone, Simforoosh and colleagues report resolution in $85.4 \%$ (111/130 patients), improvement in $10.8 \%(14 / 130)$, no change in $3 \%(4 / 130)$ and worsening reflux in 1 patient. Greater rates of resolution were identified in lower grades of reflux: $100 \%$ grades I to $\mathrm{III}, 87.5 \%$ grade IV and $61.5 \%$ grade $V(11)$. This is contrary to the findings of Lopez Pereira and colleagues that found greater rates of resolution in high-grade reflux than in low-grade reflux ( $81.2 \%$ vs. $50 \%)$. They hypothesize that lower grade VUR may be related to a congenital anomaly at the UVJ and not due to increased intravesical pressure as in higher grade reflux (7).

Soylet and colleagues retrospectively reviewed their center's experience comparing patients with VUR that had augmentation cystoplasty alone with those that had anti-reflux surgery at the time of augmentation. Fifteen children with neurogenic bladder, exstrophy-epispadias and posterior urethral valves underwent augmentation with no anti-reflux procedure while 23 patients with the same pathologies underwent augmentation with anti-reflux surgery at the same time or after augment. Grades of reflux (II to V) were similar in both groups. Interestingly, reflux resolved in $97 \%$ of the refluxing units in the group without anti-reflux surgery and $93 \%$ in the reimplant group. They conclude that reimplantation has no significant effect on the resolution of VUR even in cases of exstrophy with short submucosal ureteric tunnels (12).

Certain surgeons argue that only low-grade reflux will resolve with augmentation and opt to reimplant ureters with higher-grade reflux $(3,5,6)$. Hayashi and colleagues performed ureteral reimplantation in all patients with VUR $\geq$ grade III at the time of sigmoid bladder augmentation. The area of reimplantation was dependent on the condition of the bladder mucosa and included the native bladder or colon cap. Eighty-eight percent (66/75 kidneys) had resolution of their VUR with ureteral reimplantation. Two patients with grade I VUR pre-operatively had grade I reflux post- 
operatively. The reasons offered for simultaneous reimplantation include the need for long-term antibiotic prophylaxis in refluxing ureters and potential for malignancy resulting from recurrent UTI due to VUR (13). In our opinion, reimplantation may decrease the incidence of renal scarring but it may not decrease the incidence of UTI in the augmented bladder and should not necessarily be advocated as a means to decrease the risk of malignancy.

In several studies, the rate of resolution of reflux with augmentation alone is similar to that for patients with neuropathic bladder with normal or moderately impaired compliance that have undergone reimplantation $192 \%$ vs. $95.5 \%)(8,9,18)$.

\section{TECHNIQUES FOR CORRECTION OF VESICOURETE- RAL REFLUX IN NEUROPATHIC BLADDERS}

Reflux has been managed successfully both endoscopically and surgically in patients with neuropathic bladders. However, it is of utmost importance that bladder function is assessed with urodynamic studies prior to intervening. It is our opinion that reimplanting a ureter into a small, poorly complaint bladder is dangerous as it may lead to technical failure and further renal injury. Both surgical and endoscopic correction of VUR may be performed with augmentation cystoplasty.

\section{Surgical Correction}

Though technically more challenging than reimplantation into a normal bladder, reimplantation into a neuropathic bladder is possible with low complication rates. Successful reimplantation should be achieved provided that the bladder has been made sufficiently capacious and compliant.

Jeffs and colleagues first reported their experience with ureteral reimplantation in patients with neuropathic bladders that had not been augmented in 1976 (14). Several other studies have since been published with success rates ranging from $82 \%$ in a study by Merlini et al to $100 \%$ in a small study by Sullivan and colleagues $(15,16)$. Few studies compare endoscopic correction of reflux to surgical correction in this group of patients. Both Granata and colleagues and Engel and colleagues compared the two treatment modalities and found surgical therapy to be superior $(17,18)$. In the study by Granata and colleagues, 40 refluxing ureters had subureteric polytetrafluoroethylene injection with $72.5 \%$ success while 41 refluxing ureters had Cohen reimplantations with $95.5 \%$ success (17). Similarly, Engel et al reported success rates of $84.3 \%$ after Cohen ureteroneocystomy and $56.7 \%$ after subureteric polytetrafluoroethylene injection (18). This serves as proof that ureteroneocystotomy is the gold standard to which all other therapies should be compared.

When performing a ureteroneocystotomy at the time of cystoplasty or subsequent to cystoplasty, the ureter is preferentially reimplanted into the native bladder rather than into the intestinal segment. No single technique of ureteral reimplantation can be recommended as many studies involving reimplantation into a neurogenic bladder include a combination of repairs. However, it is our belief that there is less risk in using the original muscular hiatus such as in the Cohen repair. Regardless of the technique employed, one must adhere to the basic principles of reimplantation: 1) creation of an adequate submucosal tunnel with good muscle backing and 2) anastomosis of mucosa to mucosa.

Ureteral reimplantation into a gastric or intestinal segment may become necessary when there is insufficient native bladder for reimplantation. Additionally, the neuropathic bladder may be so trabeculated that developing an adequate submucosal tunnel is more easily achieved into an intestinal segment. When using a colonic segment, a flap valve mechanism may be created by tunneling the ureter within a tenia. As in any reimplant, mucosa should be sewn to mucosa, in this case ureteral mucosa to colonic mucosa. Reimplantation into the stomach segment is considerably simpler than reimplantation into the intestinal segments as

TABLE I. GRADES OF VESICOURETERAL REFLUX AND SUCCESS RATES IN OBSERVATION AND TREATMENT GROUP.

\begin{tabular}{|c|c|c|c|c|}
\hline \multirow[t]{2}{*}{ VUR Grade } & \multicolumn{2}{|c|}{ AUGMENTATION ALONE } & \multicolumn{2}{|c|}{ AUGMENTATION WITH ANTI-REFLUX SURGERY } \\
\hline & SUCCESS (\%) & FAILURE (\%) & SUCCESS (\%) & FAILURE(\%) \\
\hline I & $11 \quad(92)$ & (8) & $11 \quad(92)$ & $1 \quad(8)$ \\
\hline$\|$ & $8 \quad(100)$ & & $7 \quad(88)$ & $1(13)$ \\
\hline III & $7 \quad(78)$ & $2(22)$ & 16 (89) & $2(11)$ \\
\hline IV & $1 \quad(100)$ & & $8 \quad(100)$ & 0 \\
\hline V & 0 & & (75) & 1 (25) \\
\hline
\end{tabular}


stomach is thicker than intestine and similar in thickness to the urinary bladder. The ureter may be reimplanted into the stomach segment in a fashion similar to reimplantation into the bladder.

Successful reimplantation of the ureter into an ileal segment is much more difficult than reimplantation into other segments. In 1979, Le Duc and Camey described an original technique for non-refluxing ureteroileal anastomosis in ileal bladders (19). This was achieved by placing the ureter in a sulcus created in the ileal mucosa. They subsequently reported an $85 \%$ success rate (20). Since that time various other techniques have been described including the serous lined extramural tunnel method of Abol-Enein and Ghoneim in which the terminal ureter is covered with the full-thickness ileal wall, as well as antireflux ureteroileal reimplantation technique in which the terminal ureter is implanted in the deserosalized muscle of the ileum $(21,22)$.

\section{Endoscopic Management}

There are many reports of endoscopic therapy of reflux in patients with neurogenic voiding using materials including collagen, polydimethylsiloxane, polytetrafluoroethylene, autologous fat and dextranomer / hyaluronic acid $(2,17,18,23-30)$. Successful endoscopic correction of reflux after a single injection varies significantly from study to study ranging from $15 \%$ with collagen to $60-82 \%$ using polytetrafluoroethylene $(24,26,29)$. There are scant reports of the use of dextranomer/hyaluronic acid in this population. In a subset of patients with neurogenic bladders, 78\% success is reported (23). As urodynamic results in this group of patients were not published it remains unclear whether success rates would improve with improving bladder dynamics. Ureteral obstruction secondary to dispersion of the material is a known complication $(23,31)$.

\section{RILEY HOSPITAL FOR CHILDREN EXPERIENCE}

We retrospectively reviewed the charts of 185 patients that underwent augmentation cystoplasty between January 1997 and June 2003. Of these patients 65 had vesicoureteral reflux at the time of augmentation. Five patients were excluded for insufficient post-operative imaging available for our review. The decision to perform corrective surgery was determined on a case-by-case basis at the discretion of the surgeon. Several factors influenced the decision to proceed with anti-reflux surgery including the grade of reflux, history of prior pyelonephritis, need for concomitant bladder neck repair and the patient's body habitus. We believe that performing ureteral reimplantation after an augmentation cystoplasty may be significantly more difficult than performing a simultaneous reimplantation.

\section{Expectant Management Of VUR At Time Of Augmentation Cystoplasty}

Twenty-three patients with 30 refluxing ureters did not undergo reimplantation at the time of augmentation.
Seven patients (30\%) had bilateral VUR, 16 patients $(70 \%)$ had unilateral VUR (9 left, 7 right). Reflux was grade III or less in 29/30 ureters. Reflux resolved in $90 \%$ of ureters, $87 \%$ patients (20 patients, 27 ureters) (Table I). In the 3 myelodysplastic patients that failed expectant therapy (1 grade I, 2 grade III, preoperatively) each went on to surgical correction after normal urodynamic evaluation.

\section{Surgical intervention for VUR At Time Of Augmentation Cystoplasty}

Thirty-seven patients with 56 refluxing ureters had surgical intervention for VUR at the time of augmentation. Four patients underwent unilateral nephrectomy for reflux nephropathy ( 2 had bilateral VUR and underwent reimplantation of the remaining unit at the time of nephrectomy and augmentation cystoplasty). Four patients had bilateral Cohen reimplantations as part of a modified Young-DeesLeadbetter bladder neck repair at the time of augmentation (2 had unilateral VUR preoperatively, 2 had bilateral VUR preoperatively).

Correction of reflux with ureteroneocystostomy was attempted in 35 patients (50 ureters). Fifteen patients $(43 \%)$ had bilateral VUR; 20 patients $(57 \%)$ had unilateral VUR. The techniques used included 23 Cohen ( 7 tapered), 6 Politano-Leadbetter, 3 Glenn Anderson and 3 Gil-Vernet. Postoperatively, 29 patients (84\%) had no evidence of VUR. Reflux had been corrected in 45 of 50 ureters (90\%) (Table I). In patients that had pesistent VUR, 2 had lower grade unilateral reflux after unilateral correction, 2 had unilateral VUR after bilateral attempt at correction, 1 was unchanged and 1 developed contralateral VUR.

\section{RESULTS}

Observation was most commonly chosen in patients with lower grades of VUR, particularly those with unilateral reflux. In our series, conservative management of Grade I or II reflux at the time of bladder augmentation was successful in most cases, as supported by prior studies. In our patient review, the trend was to reimplant ureters with higher grades of VUR. There was no clear correlation between grade of reflux and success of reimplant in patients.

Based on our review, we cannot conclude that reimplantation is more successful than observation or vice versa.

Certainly, reimplantation after bladder augmentation is technically more challenging than performing the surgery at the time of augmentation. Determining whether correction of VUR is necessary for higher grades of reflux at the time of augmentation would require randomized prospective study. 


\section{REFERENCES AND RECOMENDED READINGS (*of special interest, ${ }^{* *}$ of outstanding interest)}

1. ATALA, A.; KEATING, M.A.: "Vesicoureteral reflux and megaureter". Walsh PC, Retik AB, Vaughan ED, Wein AJ eds, Campbell's Urology, Vol. 3 Chapter 59, 8th ed. Philadelphia: WB Saunders Co, pp. 2053-2116, 2002.

2. MISRA, D.; POTTS, S.R., BROWN, S. y cols.: "Endoscopic treatment of vesicoureteral reflux in neurogenic bladder-8 years experience”. J. Pediatr. Surg., 31: 1262, 1996.

3. AGARWAL, S.K.; KHOURY, A.E.; ABRAMSON, R.P. y cols.: "Outcome analysis of vesicoureteral reflux in children with myelodysplasia". J. Urol., 157: 980, 1997.

4. KASABIAN, N.G.; BAUER, S.B.; DYRO, F.M. y cols.: "The prophylactic value of clean intermittent catheterization and anticholinergic medication in newborns with myelodysplasia at risk for developing urinary tract deterioration". Am. J. Dis. Child., 146: 840, 1992.

5. MORIOKA, A.; MIYANO, T.; ANDO, K. y cols.: "Management of vesicoureteral reflux secondary to neurogenic bladder". Pediatr. Surg. Int., 13: 584, 1998.

6. HENDREN, W.H.; HENDREN, R.B.: "Bladder augmentation: Experience with 129 children and young adults". J. Urol., 144: 445, 1990.

7. LOPEZ PERIERA, P.; MARTINEZ URRUTIA, M.J.; LOBATO ROMERA, R. y cols.: "Should we treat vesicoureteral reflux in patients who simultaneously undergo bladder augmentation for neuropathic bladder?'. J. Urol., 165: 2259, 2001.

8. NASRALLAH, P.F.; ALIBADI, H.A.: "Bladder augmenattion in patients with neurogenic bladder and vesicoureteral reflux". J. Urol., 146: 563, 1991.

9. KRISHNA, A.; GOUGH, D.C.S.: "Evaluation of augmentation cystoplasty in childhood with reference to vesico-ureteral reflux and urinary tract infection”. Br. J. Urol., 74: 465, 1994.

10. COMARR, A.E.; BORS, E.: "Further observations on vesicoureteral reflux". J. Urol., 74: 59, 1955.

*11. SIMFOROOSH, N.; TABIBI, A.; BASIRI, A. y cols.: "Is ureteral reimplantation necessary during augmentation cystoplasty in patients with neurogenic bladder and vesicoureteral reflux?". J. Urol., 168: 1439, 2002.

*12. SOYLET, Y.; EMIR, H.; ILCE, Z. y cols.: "Quo vadis? Ureteric reimplantation or ignoring reflux during augmenattion cystoplasty". Br. J. Urol., 94: 379, 2004.

13. HAYASHI, Y.; YAMATAKA, A.; KANEYAMA, Z. y cols.: "Review of 86 patients with myelodysplasia and neurogenic bladder who underwent sigmoidocolocystoplasty and were followed more than 10 years". J. Urol., 176: 1806, 2006.

14. JEFFS, R.D.; JONAS, P.; SCHILLINGER, J.F.: "Surgical correction of vesicoureteral reflux in children with neurogenic bladder". J. Urol., 15: 449, 1976.

15. MERLINI, E.; BESEGHI, U.; DE CASTRO, R. y cols.: "Treatment of vesicoureteral reflux in the neurogenic bladder". Br. J. Urol., 72: 969, 1993.
16. SULLIVAN, T.; PURCELL, M.M.; GREGORY, J.G.: "The management of vesicoureteral reflux in the pediatric neurogenic bladder". J. Urol., 125: 65, 1981.

17. GRANATA, C.; BUFFA, P.; DI ROVASENDA, E.: y cols.: "Treatment of vesico-ureteric reflux in children with neuropathic bladder: A comparison of surgical and endoscopic correction”. J. Ped. Surg., 34: 1836, 1999.

**18. ENGEL, J.D.; PALMER, L.S.; CHENG, E.Y. y cols.: "Surgical versus endoscopic correction of vesicoureteral reflux in children with neurogenic bladder dysfunction”. J. Urol., 157: 2291, 1997.

19. LE DUC, A.; CAMEY, M.: "Un procede d'implantation ureterileale antireflux dans l'eneterocystoplastie". J. D’Urol., 85: 449, 1979.

20. LE DUC, A.; CAMEY, M.; TEILLAC, P.: “An original antireflux ureteroileal implantation technique: Longterm follow up". J. Urol., 137: 1156, 1987.

21. ABOL-ENEIN, H.; GHONEIM, M.A.: "A novel uretero-ileal reimplantation technique: The serous lined extramural tunnel. A preliminary report". J. Urol., 151: 1193, 1994.

22. SHIOJI, Y.; MURAISHI, O.; TOKUE, A.: “A deserosalized muscle layer covering method for antireflux ureteroileostomy: A preliminary clinical trial". J. Urol., 168: 2521, 2002.

*23. PEREZ-BRAYFIELD, M.; KIRSCH, A.J.; HENSLE, T.W. y cols.: "Endoscopic treatment with dextranomer/ hyaluronic acid for complex cases of vesicoureteral reflux". J. Urol., 172: 1614, 2004.

24. HAFERKAMP, A.; MOHRING, K.; STAEHLER, G. y cols.: "Long-term efficacy of subureteral collagen injection for Endoscopic treatment of vesicoureteral reflux in neurogenic bladder cases". J. Urol., 163: 274, 2000.

25. SHAH, N.; KABIR, M.J.; LANE, T. y cols.: "Vesicoueteric reflux in adults with neuropathic bladders treated with Polydimethylsiloxane (Macroplastique)". Spinal. Cord., 39: 92, 2001.

26. PURI, P.; GUINEY, E.J.: "Endoscopic correction of vesicoureteric reflux secondary to neuropathic bladder". Br. J. Urol., 58: 504, 1986.

27. QUINN, F.M.; DIAMOND, T.; BOSTON, V.E.: "Endoscopic management of vesico-ureteric reflux in children with neuropathic bladder secondary to myelomeningocele". Zeitschrift fur Kinderchirurgie, 2: 43, 1988.

28. DEWAN, P.A.; GUINEY, E.J.: "Endoscopic correction of vesicoureteric reflux in children with spina bifida". Br. J. Urol., 65: 646, 1990.

29. KAMINETSKY, J.C.; HANNA, M.K.: "Endoscopic treatment of vesicoureteral reflux in children with neurogenic bladders". Urology, 37: 244, 1991.

30. CHANCELLOR, M.B.; RIVAS, D.A.; LIBERMAN, S.N. y cols.: "Cystoscopic autogenous fat injection treatment of vesicoureteral reflux in spinal cord injury". J. Am. Paraplegia Soc., 17: 50, 1994.

31. VANDERSTEEN, D.R.; ROUTH, J.C;. KIRSCH, A.J. y cols.: "Postoperative ureteral obstruction after subureteral injection of dextranomer/hyaluronic Acid copolymer". J. Urol., 176: 1593, 2006. 